\title{
Risk of Developing Pyoderma Gangrenosum after Procedures in Patients with a Known History of Pyoderma Gangrenosum - A Retrospective Analysis
}

\section{Citation}

Xia, Fandi D., Kristina J. Liu, Steven J. Lockwood, Daniel C. Butler, William G. Tsiaras, Cara Joyce, and Arash Mostaghimi. 2017. Risk of developing pyoderma gangrenosum after procedures in patients with a known history of pyoderma gangrenosum - a retrospective analysis. Journal of American Dermatology. doi: 10.1016/j.jaad.2017.09.040.

\section{Published Version}

10.1016/j.jaad.2017.09.040

\section{Permanent link}

http://nrs.harvard.edu/urn-3:HUL.InstRepos:34216317

\section{Terms of Use}

This article was downloaded from Harvard University's DASH repository, and is made available under the terms and conditions applicable to Open Access Policy Articles, as set forth at http:// nrs.harvard.edu/urn-3:HUL.InstRepos:dash.current.terms-of-use\#OAP

\section{Share Your Story}

The Harvard community has made this article openly available.

Please share how this access benefits you. Submit a story. 
Article type: Original article

Title: Risk of Developing Pyoderma Gangrenosum after Procedures in Patients with a Known History of Pyoderma Gangrenosum - A Retrospective Analysis

Fan Di Xia*, AB

Brigham \& Women's Hospital, Harvard Medical School, Boston, MA

Kristina Liu*, MD

Department of Dermatology, Brigham \& Women's Hospital, Harvard Medical School,

Boston, MA.

Stephen Lockwood, MD, MPH

Clinical Unit for Research Trials in Skin, Department of Dermatology, Massachusetts General

Hospital, Harvard Medical School, Boston, MA, USA

Daniel Butler, MD

Harvard Combined Dermatology Residency Training Program

William G. Tsiaras, MD, PhD

Department of Dermatology, Brigham \& Women's Hospital, Harvard Medical School, Boston, MA.

Cara Joyce, $\mathrm{PhD}$

Loyola University, Chicago, IL.

Arash Mostaghimi, MD, MPA, MPH

Department of Dermatology, Brigham \& Women's Hospital, Harvard Medical School, Boston, MA.

*co-first authors

\section{Corresponding author:}

Arash Mostaghimi, M.D., M.P.A., M.P.H.

Assistant Professor of Dermatology, Harvard Medical School

Brigham and Women's Hospital

75 Francis Street, PBB-B 421

Boston, MA 02115

amostaghimi@bwh.harvard.edu

Phone: 617-525-8335

Fax: 617-525-3177

44

45

46

Funding sources: None 
47

48

49

50

51

52

53

54

55

56

57

58

59

60

61

62

63

IRB approval status: Reviewed and approved by Partners healthcare IRB

Conflicts of Interest: None declared

Reprint requests: Arash Mostaghimi, MD, MPA, MPH

Prior Presentation: Late-Breaking Research Symposium of the 2017 Annual Meeting of the American Academy of Dermatology. Orlando, FL. March 2017.

Abstract Word Count: 199

Capsule Summary Word Count: 50

Manuscript Word count: 1354

Table count: 3

Supplementary table count: 1

References: 7 
64

65

66

67

68

69

70

\section{Abstract}

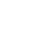

Background: The risk of postoperative pyoderma gangrenosum (PG) in patients with a known history of PG is unknown.

Objective: To quantify risk and identify patient/procedure-related risk factors for postsurgical PG recurrence/exacerbation in patients with known history of PG.

Methods: We retrospectively evaluated the likelihood of postsurgical PG recurrence/exacerbation for all patients with a confirmed diagnosis of PG at Brigham \& Women's Hospital and Massachusetts General Hospital from 2000-2015.

Results: $5.5 \%(n=33)$ of procedures led to recurrence of PG in $15.1 \%(n=25)$ of patients. Compared to skin biopsy, small open surgeries had an adjusted odds ratio (aOR) of 8.65 (1.55, 48.33) for PG recurrence/exacerbation; large open surgeries had an aOR of 5.97 (1.70, 21.00); and Mohs surgery/skin excision had an aOR of $6.47(1.77,23.61)$. PG chronically present at the time of procedure had an aOR of $4.58(1.72,12.22)$. Immunosuppression, time elapsed since original PG diagnosis, and procedure location did not significantly influence risk.

Limitations: Our study is limited by its retrospective nature and relatively small sample size. 
86 Conclusion: There is a small but clinically meaningful risk of postsurgical PG

87 recurrence/exacerbation in patients with known history of PG; higher risks occur with more

88 invasive procedures and chronically present PG.

89

90 Keywords: Pyoderma gangrenosum, pathergy, risk factors, postoperative, recurrence,

91 exacerbation, prophylaxis

92 


\section{Capsule Summary}

95

96 - The risk of postoperative pyoderma gangrenosum (PG) in patients with history of PG is 97 unknown.

98 - $15.1 \%$ of patients experienced postsurgical PG recurrence/exacerbation; risk increased 99 with more invasive procedures and chronic PG at the time of the procedure.

100 - There is a small but clinically meaningful risk of postsurgical PG in patients with a $101 \quad$ known history of PG.

102 


\section{Introduction}

105 Pyoderma gangrenosum (PG) is a neutrophilic process characterized by pathergy. ${ }^{1}$ Postoperative

106 PG as a primary phenomenon has been characterized in the literature as being less likely

107 associated with systemic diseases, with onset usually in the first week after the procedure is

108 performed. ${ }^{2,3}$

109

110 Little is known about the risk for postoperative PG or recurrence/exacerbation of PG in patients

111 with a known history of PG. Quantifying overall and procedure-specific risks for postoperative

112 PG recurrence/exacerbation may affect medical decision making for patients with known history

113 of PG, such as initiating prophylactic immunosuppression prior to procedures or

114 avoiding/adjusting the timing of elective procedures. In this study, we aim to evaluate the risk for

115 PG recurrence or exacerbation after different types of procedures in patients with a known

116 history of PG.

118 Methods

119 We searched the Research Patient Data Repository, a database of the medical records of all

120 patients seen at Partners Healthcare, for patients with PG who underwent procedures at the

121 Brigham \& Women's Hospital and Massachusetts General Hospital from 2000-2015 using the

122 International Classification of Diseases, Ninth Revision, Clinical Modification (ICD-9-CM) code

123 (686.01) for pyoderma gangrenosum. Medical records of returned cases were individually

124 reviewed to confirm a diagnosis of PG using previously described major and minor criteria

125 suggestive of PG diagnosis. ${ }^{4}$ Relevant information regarding the original PG and all subsequent 
surgical procedures underwent by the patient since the original PG diagnosis were extracted, with the primary outcome being PG exacerbation or recurrence within 30 days of the procedure. All data were managed using REDCap (Research Electronic Data Capture). ${ }^{5}$ Patients without a diagnosis of PG, subsequent procedures, or adequate clinical documentation were excluded.

The types of procedures examined were 1) skin biopsies, 2) minimally invasive surgeries/small needle injections such as laparoscopies, arthroscopies, core-needle biopsies, and epidural injections, 3) small open surgeries such as thyroid surgeries and lumpectomies, 4) large open surgeries such as exploratory laparotomies and colectomies, and 5) Mohs surgery/skin excision and debridement (Supplementary Table 1). Chronically present PG at the time of surgery was defined as PG present for $>1$ year at the time of surgery or per clinician documentation.

Procedure-level and patient-level PG recurrence rates were presented for patient demographics and clinical characteristics. Univariable and multivariable analysis was performed using logistic regression mixed models. Random intercepts were included in the regression models to account for possible within-person correlation for patients with multiple additional procedures. Variables with $\mathrm{p}<0.10$ from the univariable analysis were included in the multivariable regression model. Adjusted and unadjusted odds ratios were calculated. All analyses were performed using SAS 9.4 (Cary, NC). This study was approved by the Partners Healthcare Institutional Review Board. 
148 Of the 530 patients identified using ICD-9-CM codes for PG, 166 patients met inclusion criteria

149 with a confirmed diagnosis of PG and subsequent procedures. Each patient underwent a median

150 of 2 (interquartile range 1,4) additional surgeries, for a total of 601 surgeries evaluated. The

151 mean age was 52.8 years, and $80.1 \%(n=133)$ were women. The most common PG related

152 comorbidity was inflammatory bowel disease $(44.6 \%, \mathrm{n}=74)$, and the most common location of

153 original PG was on the lower extremities $(57.8 \%, \mathrm{n}=96)$ (Table 1).

155 We found a total of 33 cases of postsurgical PG exacerbation/recurrence, occurring in 25

156 patients, accounting for a recurrence rate of $5.5 \%(33 / 601)$ by procedure (Table 2$)$ and $15.1 \%$

$157(25 / 166)$ by patient. Univariable analysis at the procedure level demonstrated that the

158 exacerbation/recurrence rate was significantly associated with procedure type $(p=0.022)$ and

159 having chronically present PG at the time of procedure $(\mathrm{p}=0.041)$ (Table 2$)$. Age $\geq 60$ at time of

160 surgery, sex, comorbidities, location of the original PG/surgery, location of surgery being at the

161 same site as original PG, new/expanding/multifocal PG at the time of procedure, chronic or

162 prophylactic immunosuppression were not statistically significant predictors of PG recurrence.

163 Furthermore, time elapsed since the original PG and the additional surgery also were not

164 associated with recurrence.

165

166 Multivariable regression modeled exacerbation/recurrence as a function of age at time of

167 surgery, chronically present PG, and procedure types $(\mathrm{p}<0.10)$. Age $\geq 60$ at time of surgery was

168 associated with increased odds of PG recurrence and was of marginal statistical significance with

169 an adjusted odds ratio (aOR) of 2.41 (95\% CI: 0.92, 6.39). Compared to risk of recurrence after

170 skin biopsies, minimally invasive surgeries/small needle injections had similar risk for PG 

recurrence.

\section{Discussion}

recurrence with an aOR of 0.96 (95\% CI: 0.16-5.60). Other procedure types were associated with increased odds of recurrence, with an aOR of 8.65 (95\% CI: 1.55-48.33) for small open surgeries, an aOR of 5.97 (95\% CI: 1.70-21.00) for large open surgeries, and an aOR of 6.47 (95\% CI: 1.77-23.61) for Mohs surgery/skin excision (Table 3). Chronically present PG at the time of surgery had an aOR of 4.58 (95\% CI: 1.72-12.22).

In a sensitivity analysis, we examined the relationship between patient-level characteristics at the time of first surgery with recurrence/exacerbation $(n=166)$; age, gender, comorbidities, location of PG, multifocal ulcer, and chronic immunosuppression were not significantly associated with recurrence in this study.

While pathergy associated with PG is a well-known phenomenon, our study found that the risk of postsurgical PG recurrence or exacerbation in patients with known history of PG is relatively low at 5.5\% (33/601 surgeries). However, recurrence/exacerbation occurred in 15.1\% (25/166 patients) of our patients, suggesting that the per-patient risk for experiencing a recurrence of postsurgical PG recurrence/exacerbation is clinically relevant. Independent risk factors influencing PG recurrence/exacerbation post-procedure were procedure type and having chronic PG at the time of procedure. More invasive procedures such as small and large open surgeries, 
194 This study builds on existing literature in PG by quantifying the risk of postsurgical PG recurrence/exacerbation in patients with known history of PG, which will help inform patients and physicians when assessing the risk of surgical procedures. In general, the greater the amount of tissue manipulation, the higher the likelihood of subsequent PG. This concept has face validity and is consistent with the current understanding of the pathophysiology of PG and pathergy, which is thought to involve dysfunction and up-regulation of neutrophil activities. ${ }^{6,7}$ Invasive surgeries are likely associated with more tissue manipulation, inflammation and surgical stress. Time elapsed between the original PG diagnosis and surgery, did not significantly influence recurrence risk, suggesting that the neutrophilic dysfunction of PG may be intrinsic to the host with limited change over time.

Chronic or prophylactic immunosuppression leading up to surgery did not significantly influence recurrence risk in our study. However, this finding may reflect confounding by indication in that the use of chronic immunosuppression may be correlated with baseline severity of original PG, which was not a variable that we could account for due to lack of standardized clinical assessments. As such, further studies are needed to evaluate the current practice or efficacy of prophylactic immunosuppression prior to procedures in patients with history of PG.

While we identified independent predictors of recurrence risk on a procedure level, we did not find clinical factors that significantly predicted risk at the patient level. Smaller sample size on a per patient basis (25 patients with PG recurrences vs. 33 procedures complicated by PG recurrence) may have limited our ability to detect significant factors. 
217 The results of this study must be interpreted in the context of our study design. Recurrent PG is

218 rare, thereby limiting our ability to detect differences in recurrence risk between small open,

219 large open, and Mohs surgery/skin excision procedures. The small sample sizes may also limit

220 our detection of significance when examining risk factors at the patient level as discussed above.

221 Future studies should confirm our findings in larger, multi-centered, prospective trials, especially

222 evaluating whether risk factors identified in our study can be modified to decrease the risk of

223 postsurgical PG recurrence/exacerbation.

225 Conclusion:

226 We conclude that there exists a small but clinically meaningful risk of postsurgical PG

227 recurrence/exacerbation in patients with a known history of PG, with higher risks seen with more

228 invasive procedures and in patients with chronically present PG at the time of surgery. Time

229 elapsed between the original PG diagnosis, and surgery and prophylactic immunosuppression did not significantly affect the rate of PG recurrence. 
233

234

235

236

237

238

239

240

241

242

243

244

245

246

247

248

249

250

251

252

253 254

\section{References}

1. Binus AM, Qureshi AA, Li VW, Winterfield LS. Pyoderma gangrenosum: a retrospective review of patient characteristics, comorbidities and therapy in 103 patients. The British journal of dermatology. Dec 2011;165(6):1244-1250.

2. Tolkachjov SN, Fahy AS, Cerci FB, Wetter DA, Cha SS, Camilleri MJ. Postoperative Pyoderma Gangrenosum: A Clinical Review of Published Cases. Mayo Clinic proceedings. Sep 2016;91(9):1267-1279.

3. Tolkachjov SN, Fahy AS, Wetter DA, et al. Postoperative pyoderma gangrenosum (PG): the Mayo Clinic experience of 20 years from 1994 through 2014. Journal of the American Academy of Dermatology. Oct 2015;73(4):615-622.

4. Su WP, Davis MD, Weenig RH, Powell FC, Perry HO. Pyoderma gangrenosum: clinicopathologic correlation and proposed diagnostic criteria. International journal of dermatology. Nov 2004;43(11):790-800.

5. Harris PA, Taylor R, Thielke R, Payne J, Gonzalez N, Conde JG. Research electronic data capture (REDCap) — a metadata-driven methodology and workflow process for providing translational research informatics support. J Biomed Inform. 2009;42(2):377-381. 
255 6. Braswell SF, Kostopoulos TC, Ortega-Loayza AG. Pathophysiology of pyoderma

256 gangrenosum (PG): an updated review. Journal of the American Academy of Dermatology. Oct $257 \quad 2015 ; 73(4): 691-698$.

258

259 7. Alavi A, French LE, Davis MD, Brassard A, Kirsner RS. Pyoderma Gangrenosum: An Update 260 on Pathophysiology, Diagnosis and Treatment. American journal of clinical dermatology. Jun $261 \quad 2017 ; 18(3): 355-372$. 
264 Table 1: Patient characteristics

\begin{tabular}{l|r}
\hline $\mathrm{n}(\%)$ & $\begin{array}{r}\text { Overall } \\
\mathrm{n}=166\end{array}$ \\
\hline Age at PG diagnosis & $97(58.4)$ \\
\hline$<60$ & $69(41.6)$ \\
\hline$\geq 60$ & \\
\hline Gender & $33(19.9)$ \\
\hline Male & $133(80.1)$ \\
\hline Female & \\
\hline Comorbidities & $74(44.6)$ \\
\hline Ulcerative colitis, Crohn's disease & $22(13.3)$ \\
\hline Hematologic disorder & $16(9.6)$ \\
\hline Solid malignancy & $46(27.7)$ \\
\hline Arthritis & $14(8.4)$ \\
\hline Psoriasis & $28(16.9)$ \\
\hline Diabetes & $15(9.0)$ \\
\hline PVD & $23(13.9)$ \\
\hline No relevant comorbidities & $16(9.6)$ \\
\hline Other (pertaining to PG) & \\
\hline Location of original PG & $10(6.0)$ \\
\hline Head/neck & $65(39.2)$ \\
\hline Trunk & $16(9.6)$ \\
\hline Upper extremities & $12(7.2)$ \\
\hline Groin/genitals & $96(57.8)$ \\
\hline Lower extremities & \\
\hline Number of additional surgeries & $52(31.3)$ \\
\hline 1 & $56(33.7)$ \\
\hline $2-3$ & $58(34.9)$ \\
\hline$\geq 4$ &
\end{tabular}

For results section:

mean (SD) age: 52.8 (17.6)

268

median (interquartile range) additional surgeries: $2(1,4)$ 
271

Table 2: Characteristics of additional surgeries and recurrence

\begin{tabular}{|c|c|c|c|}
\hline & $\begin{array}{r}\text { No. } \\
\text { surgeries }\end{array}$ & $\begin{array}{l}\mathrm{n}(\%) \text { with } \\
\text { recurrences }\end{array}$ & $\mathrm{p}$-value \\
\hline Overall & 601 & $33(5.5)$ & \\
\hline Age $\geq 60$ at surgery & 269 & $21(7.8)$ & 0.063 \\
\hline Female & 485 & $27(5.6)$ & 0.927 \\
\hline Comorbidities & & $\mathrm{ar}$ & \\
\hline Ulcerative colitis, Crohn's disease & 322 & $14(4.3)$ & 0.317 \\
\hline Hematologic disorder & 69 & $2(2.9)$ & 0.351 \\
\hline Solid malignancy & 72 & $3(4.2)$ & 0.536 \\
\hline Arthritis & 252 & $11(4.4)$ & 0.499 \\
\hline Psoriasis & 66 & $5(7.6)$ & 0.469 \\
\hline Diabetes & 115 & $10(8.7)$ & 0.173 \\
\hline PVD & 58 & $1(1.7)$ & 0.239 \\
\hline No relevant comorbidities & 68 & $5(7.4)$ & 0.551 \\
\hline Other (pertaining to $\mathrm{PG}$ ) & 46 & $3(6.5)$ & 0.698 \\
\hline \multicolumn{4}{|l|}{ Location of original PG (may be more than one) } \\
\hline Head/neck & 44 & $0(0.0)$ & -- \\
\hline Trunk & 246 & $16(6.5)$ & 0.441 \\
\hline Upper extremities & 53 & $4(7.5)$ & 0.439 \\
\hline Groin/genitals & 32 & $0(0.0)$ & -- \\
\hline Lower extremities & 351 & $17(4.8)$ & 0.385 \\
\hline \multicolumn{4}{|l|}{ Time between original diagnosis and additional surgery } \\
\hline$<1$ year & 184 & $11(6.0)$ & \\
\hline $1-2$ years & 125 & $6(4.8)$ & 0.765 \\
\hline$\geq 2$ years & 292 & $16(5.5)$ & \\
\hline \multicolumn{4}{|l|}{ Location of additional surgery } \\
\hline Head/neck & 76 & $2(2.6)$ & \\
\hline Trunk & 250 & $12(4.8)$ & \\
\hline Upper extremities & 44 & $3(6.8)$ & 0.755 \\
\hline Groin/genitals & 86 & $5(5.8)$ & \\
\hline Lower extremities & 145 & $11(7.6)$ & \\
\hline Additional surgery in same location as original PG & 180 & $8(4.4)$ & 0.318 \\
\hline Multifocal ulcer at time of diagnosis & 246 & $16(6.5)$ & 0.350 \\
\hline Procedure type & & & \\
\hline Skin biopsy & 209 & $6(2.9)$ & \\
\hline $\begin{array}{l}\text { Minimally invasive surgeries / small needle } \\
\text { injections* }\end{array}$ & 116 & $2(1.7)$ & \\
\hline Small open surgeries & 43 & $4(9.3)$ & 0.022 \\
\hline Large open surgeries & 129 & $10(7.8)$ & \\
\hline Mohs surgery / skin excision & 104 & $11(10.6)$ & \\
\hline Chronic immunosuppression & 313 & $15(4.8)$ & 0.637 \\
\hline Started immunosuppression for procedure & 5 & $1(20.0)$ & 0.216 \\
\hline Chronically present PG at time of procedure & 173 & $15(8.7)$ & 0.041 \\
\hline
\end{tabular}




\begin{tabular}{l|r|r|r}
\hline New/expanding PG at time of procedure & 48 & $5(10.4)$ & 0.172 \\
\hline
\end{tabular}

273 *includes: cardiac catheterization, laparoscopy, arthroscopy, thoracoscopy, core needle biopsy,

274 epidural or other small needle injection;

275 p-values from generalized linear mixed models with random intercepts for patients with multiple

276 additional procedures, binomial distribution and logit link 
Table 3: Odds ratios for associations between patient and procedure characteristics and recurrence

\begin{tabular}{|c|c|c|}
\hline & $\begin{array}{r}\text { Unadjusted Odds } \\
\text { Ratio } \\
\text { (95\% Confidence } \\
\text { Interval) } \\
\end{array}$ & $\begin{array}{r}\text { Adjusted Odds Ratio } \\
\text { (95\% Confidence } \\
\text { Interval) }\end{array}$ \\
\hline Overall & & $n$ \\
\hline Age $\geq 60$ at surgery & $2.31(0.96,5.56)$ & $2.41(0.92,6.39)$ \\
\hline \multicolumn{3}{|l|}{ Procedure type } \\
\hline Skin biopsy & 1 (Reference) & 1 (Reference) \\
\hline $\begin{array}{l}\text { Minimally invasive surgeries / small needle } \\
\text { injections* }\end{array}$ & $0.62(0.11,3.50)$ & $0.96(0.16,5.60)$ \\
\hline Small open surgeries & $3.34(0.66,16.88)$ & $8.65(1.55,48.33) \dagger$ \\
\hline Large open surgeries & $3.57(1.08,11.84) \dagger$ & $5.97(1.70,21.00) \ddagger$ \\
\hline Mohs surgery/skin excision & $5.92(1.71,20.44) \div$ & $6.47(1.77,23.61) \neq$ \\
\hline PG present at time of procedure & $3.31(1.41,7.76) \neq$ & $4.58(1.72,12.22) \ddagger$ \\
\hline
\end{tabular}

281 *includes: cardiac catheterization, laparoscopy, arthroscopy, thoracoscopy, core needle biopsy,

282 epidural or other small needle injection

$283 \uparrow \mathrm{p}<0.05 ; \uparrow \mathrm{p}<0.01$

284 Odds ratios from generalized linear mixed models with random intercepts for patients with

285 multiple additional procedures, binomial distribution and logit link. Variables with $\mathrm{p}<0.10$ from

286 univariable analysis included. 
289 Supplementary Table 1: Examples of procedures by category

290

\begin{tabular}{|c|c|}
\hline Skin Biopsies & $\begin{array}{ll}- & \text { Shave biopsy } \\
\text { - } & \text { Punch biopsy }\end{array}$ \\
\hline $\begin{array}{l}\text { Minimally Invasive Surgeries/Small } \\
\text { Needle Injections }\end{array}$ & $\begin{array}{ll}\text { - } & \text { Laparoscopy } \\
- & \text { Arthroscopy } \\
\text { - } & \text { Core-needle biopsy } \\
- & \text { Epidural injection } \\
- & \text { Percutaneous Endoscopic Gastrostomy } \\
& \text { (PEG) }\end{array}$ \\
\hline Small Open Surgeries & $\begin{array}{ll}- & \text { Thyroid surgery } \\
\text { - } & \text { Breast lumpectomy } \\
\text { - } & \text { Axillary lymphadenectomy } \\
\text { - } & \text { Fistulotomy and placement of seton } \\
\text { - } & \text { Carpal tunnel release/trigger finger } \\
& \text { release }\end{array}$ \\
\hline Large Open Surgeries & $\begin{array}{ll}- & \text { Exploratory laparotomy } \\
\text { - } & \text { Colectomy } \\
\text { - } & \text { Total knee/hip replacement } \\
- & \text { Ileostomy revisions/takedown } \\
- & \text { Below-the-knee/foot amputation }\end{array}$ \\
\hline Mohs Surgery/Skin Excision/Debridement & $\begin{array}{ll}- & \text { Mohs surgery } \\
- & \text { Skin excision } \\
- & \text { Wound debridement }\end{array}$ \\
\hline
\end{tabular}

